\section{$102-103$ \\ Documento}

Herity o la calidad en la gestión de los bienes culturales

PH43 - Abril 2003

\title{
Herity o la calidad en la gestión de los bienes culturales
}

\section{Gestión para la conservación}

En los últimos años estamos asistiendo a un aumento del uso y disfrute social del patrimonio cultural. Tal incremento, derivado de circunstancias ya ampliamente comentadas (González: 1995, 2002; Bernadas: 1999; Ruiz y Ruíz: 2002), ha generado grandes y nuevas demandas en el ámbito de la gestión de los bienes culturales. En efecto, aunque la mayor utilidad pública de los bienes en el fondo no implica grandes cambios, pues la necesidad de preservarlos sigue siendo la premisa básica, sí genera novedades en el tratamiento, pues exige adecuación para el acceso público, prevención del deterioro que este acceso puede ocasionar y, más en general, una adecuada gestión.

Entendemos por gestión del patrimonio cultural, tal y como se hace en el contexto internacional actual, la labor de identificación, preservación y presentación al público de los restos materiales del pasado de cualquier época, región o país (Cleere 1993: 400).

Dos circunstancias han contribuido de forma concomitante al inicio de una gestión, más o menos sistemática, en el terreno del patrimonio cultural: un cambio en el modo de percibir al bien y el incremento del uso social que tal cambio genera. Así, comienza a gestionarse cuando, además de percibirse como monumento y documento del pasado, se aprecia como recurso para el presente y futuro y pretende utilizarse como tal.

En efecto, mientras los bienes históricos se valoran como documentos y monumentos (S. XIX y comienzos del XX) la actividad que cabe abordar sobre ellos es el estudio y conservación; su administración se lleva con una mínima organización de material y medios porque quien mayormente los utiliza es el investigador, no el público. La labor del Estado en ellos se concreta, sobre todo, en el control y salvaguardia. Por eso se puede decir que, más que gestionarse, los bienes culturales se tutelan. Asi fue hasta que a mediados del siglo pasado Europa se percata de hechos tales como que:

\section{$>$ La Segunda Guerra Mundial ha destrui-} do mucho patrimonio.

> La consolidación del "Estado del Bienestar" transforma los viajes y acceso minoritario a lugares de interés arqueológico (como Roma o Atenas) en viajes de masas, fomentando el interés por los bienes históricos, aunque sólo sea por los más vistosos.

$>$ El gran volumen de obras que se efectúan sobre el territorio hace que se descubran y destruyan muchos bienes...

A raiz de estas y otras circunstancias comienza a verse que los bienes culturales, además de documentos, son recursos, limitados y no renovables, y como tales han de gestionarse, pues interesan para:

> Amueblar el espacio actual y el tiempo pasado.

> Ampliar la educación reglada y no reglada. $>$ Constituir atractivos turísticos que entretienen a unos y ofrecen empleo a otros.

$>$ Contribuir a mejorar la calidad del entorno y medio ambiente ofreciendo así calidad de vida.

Como monumentos únicos y recursos no renovables, una de las primeras tareas de la gestión es garantizar su preservación y aquí nos encontramos con una gran contradicción, pues cuanto más se pretende conservar un bien más se desea usar (el público que demanda su acceso es mayor). Tal contradicción de un lado aumenta el valor de los bienes y de otro demanda una gestión de calidad que evite su deterioro. Dicho esto cabe preguntarse qué es una gestión de calidad.

\section{Calidad en la Gestión}

La definición oficial de calidad, de acuerdo con la Organización Internacional para la Estandarización (ISO), es la capacidad de un conjunto de características inherentes a un producto, sistema o proceso para cumplir los requerimientos de los clientes y otras partes interesadas (ISO
9000: 2000 tomado de Tzanidaki \& Vicinzino: 2002).

En tal sentido es preciso decir que la calidad no es sólo un producto o resultado final, sino que implica un proceso que instrumenta una serie de principios de calidad conocidos como estándares de calidad a lo largo de todo un proceso de trabajo destinado a conseguir un producto 0 servicio (Tzanidaki \& Vicinzino: 2002). En el caso del patrimonio cultural una gestión de calidad debería tener un como resultado un doble servicio: al bien, mantenimiento y conservación, y al público usuario debería proporcionar un cómodo y correcto disfrute de tal bien.

Por eso una gestión de calidad debe basarse en el respeto a los valores, materiales e inmateriales, del patrimonio y en pautas de uso sancionadas por el conjunto social (desde responsables políticos al público en general) que garanticen tanto la conservación como la producción de beneficios económicos y sociales (Quagliuolo 2002: 259).

Para responder a las anteriores exigencias de una gestión de calidad se ha diseñado el programa Herity. El acrónimo HERITY es el resultado de la unificación de dos palabras (en inglés): Patrimonio (Heritage) y Calidad (Quality). La elección de estos dos términos se debe al interés del programa en la definición de estándares para una gestión de calidad de los recursos culturales de todo tipo: museos, bibliotecas, conjuntos históricos, yacimientos arqueológicos...

En efecto, Herity surge como grupo de profesionales independientes en 1994 con la intención de implicar a profesionales e instituciones, de distintos ámbitos del patrimonio y procedencias geográficas, en la definición de una metodología de evaluación de la calidad aplicable a tipos y situaciones diversas del patrimonio cultural. Así, su principal objetivo es definir un sistema de evaluación de calidad de la gestión de los diferentes tipos de bienes patrimoniales cuyo resultado informe claramente al público usuario sobre la misma. 
En la consecución de tal objetivo en 1998 aprueba la Resolución para crear el forum internacional HERITY. En ella se definen los principios de trabajo, la estructura de su organización, los objetivos del foro y los campos de intervención (ver Anexo 1). A finales del 2001 Herity aprueba los cuatro Criterios (ver anexo 2) en los que se basará el sistema de evaluación de la calidad. En concreto son:

> Valor del bien, o importancia, material $y / 0$ inmaterial que se le atribuye.

> Potencial de Preservación, o existencia de las condiciones necesarias para el mantenimiento y acrecentamiento futuro del valor considerado en el criterio anterior.

> Información transmitida, o capacidad para dar a conocer al público los valores del lugar.

> Servicios proporcionados, actividades que fomentan la apreciación del bien y ayudan a disfrutar de su acceso.

Para evaluar la existencia y el funcionamiento satisfactorio de estos criterios se han definido 16 parámetros, áreas homogéneas dentro de las cuales se puede individualizar un número variable de requisitos, entidades singulares de evaluación que definen las condiciones imprescindibles para obtener el objetivo final del parámetro que pretende medir. Esto que asi dicho puede resultar un poco oscuro se puede clarificar con un ejemplo:

Uno de los parámetros que mide el criterio potencial de preservación es el inventario. Alguno de los requisitos que miden el buen estado de tal parámetro son, por ejemplo, la existencia o no de un archivo con supervisión científica, un archivo con registros almacenados en medios duraderos, con reglas de uso claramente establecidas... Así, los 16 parámetros se evalúan a través de 182 requisitos que serán testados en diferentes elementos de los distintos países involucrados. En este momento Herity está buscando los recursos y realizando los trabajos necesarios para abordar tal labor de testado y validación de la metodología definida.

\section{Anexo 1}

\section{DECLARACIÓN DE CALAMOSCA}

Resolución para crear el forum internacional HERITY

\section{Principios}

$>$ El patrimonio cultural es la memoria colectiva de la humanidad

$>$ El patrimonio cultural es un recurso no renovable

> La gestión del patrimonio, según criterios de calidad, debería orientarse a su preservación en el contexto del desarrollo sostenible.

\section{Estructura}

HERITY será una organización no gubernamental abierta a cualquier individuo o institución interesada en este tema y conforme con los principios anteriores. Adopta la designación de International Forum for Quality Management Of The Cultural Heritage y el arónimo de HERITY.

Una secretaría con sede en Roma (Italia), que integra a los firmantes del presente documento, coordinará la discusión y promoverá los objetivos de HERITY.

\section{Objetivos}

El objetivo de Herity es definir los requisitos mínimos adoptados a nivel internacional para una gestión según criterios de calidad del patrimonio cultural, con objetivos claramente establecidos en el ámbito de campos de intervención bien definidos.

\section{Campos de intervención}

Para alcanzar sus objetivos HERITY trabajará en tres áreas principales: Educación, Preservación y Promoción. El programa de temas a discutir incluirá: investigación e interpretación, inventarios, sistemas de información, concienciación social, conservación, turismo cultural, servicios, política territorial y planeamiento.

\section{Primeras Actividades}

HERITY abrirá una discusión pública internacional para recoger sugerencias y opiniones para diseñar propuestas sobre requerimientos de calidad en las áreas mencionadas a través de todos los medios de comunicación disponibles, en particular reuniones, conferencias, publicaciones e internet.

Firmada en Cágliari, Cerdeña, el 9 diciembre 1998.

\section{Anexo 2}

\section{RESOLUCIÓN DE BARLETTA Criterios de Evaluación de Herity}

Introducción

El Patrimonio Cultural del mundo constituye la memoria colectiva de la humanidad. Esta memoria es la suma de los lugares de patrimonio cultural que expresan la identidad de los países donde se localizan.

La calidad en la gestión del patrimonio cultural debería ser el objetivo para la preservación respetando las necesidades para el desarrollo compatible y sostenible.

Tal gestión consiste en una serie de iniciativas encaminadas a fomentar el conocimiento, conservación, difusión y disfrute de este patrimonio para beneficio de todos. Las iniciativas en favor del patrimonio cultural deben planearse cuidadosamente dado que se emprenden con:

$>$ Recursos no renovables;

$>$ El desarrollo de un sector aún no consolidado.

Las iniciativas en favor del patrimonio cultural a menudo encierran diferencias significativas respecto a:

\section{$>$ Contenidos y;}

$>$ Estrategias.

Las iniciativas en favor del patrimonio cultural llevadas a cabo a través de la cooperación incorporan problemas concernientes a:

> Normalización de los procesos;

$>$ Satisfacción de los interesados.

Por las razones anteriores, comenzando con la planificación de etapas, las iniciati- 


\section{$104-105$ \\ Documento}

Herity o la calidad en la gestión de los bienes culturales

\section{PH43 - Abril 2003}

vas en favor del Patrimonio Cultural requieren un profundo análisis, coordinación, organización y planificación y promoción a medio y largo plazo. Estas tareas se llevan a cabo por un equipo que trabaja conjuntamente donde personas, instituciones y empresas aúnan su especial pericia y precisión.

Las iniciativas en favor del patrimonio cultural deben gestionarse profesionalmente, ser interdisciplinares y necesitan un fuerte apoyo local.

La calidad en la gestión del Patrimonio Cultural debe basarse en el respeto a sus valores materiales e inmateriales y en reglas colectivas para su uso y desarrollo.

El programa Herity ha sido designado para encontrar estas necesidades fomentando el compromiso de organismos públicos y privados, asociaciones y empresas. Tiene también la intención de preparar una metodología que pueda aplicarse a situaciones diversas.

De acuerdo con los principios establecidos y publicados en la Resolución de Calamosca y aprobados en Cagliari el 9 de Diciembre de 1998 ,

siguiendo los encuentros del Foro Herity del 9 de Diciembre de 1999 y el 15 de Diciembre de 2000

considerando que se resolvió promover la discusión internacional considerando que se estimó necesario definir los requisitos mínimos para la evaluación de la Calidad en la Gestión del Patrimonio Cultural independientemente de su situación histórica, legal o geográfica

considerando que se acordó que el sistema de evaluación debe basarse en criterios claros aceptados por todos, de cara a utilizarlos para establecer los requisitos indispensables para la certificación de lugares de Patrimonio Cultural bajo el programa Herity, por la presente se establecen los siguientes

\section{Criterios}

1. Herity certificará aquellos sitios de patrimonio cultural que se gestionen de tal forma que mantengan un balance entre compatibilidad y sostenibilidad en todas las formas de intervención.

2. La certificación Herity deberá darse a conocer a todos aquellos que tengan cualquier contacto con el sitio, y en particular al público.

3. La certificación se basará en una evaluación de la gestión de los sitios con relación al grado de su:

$>$ Valor considerado;

> Potencial de preservación;

> Información transmitida;

$>$ Servicios proporcionados.

4. Valor considerado se refiere a la importancia material e inmaterial generalmente atribuida al lugar, independientemente de cualquier razón.

5. Potencial de preservación es la existencia de condiciones para la creación, mantenimiento y acrecentamiento en el tiempo del valor considerado antes mencionado.

6. Información transmitida es el conjunto de iniciativas tomadas para la difusión de conocimiento y conciencia del mencionado valor percibido.

7. Servicios proporcionados son todas aquellas actividades, directas o indirectas, que fomentan la apreciación optima de los valores del sitio de patrimonio cultural considerado. 8. El conjunto de criterios aqui vistos servirá como base para redactar una lista de requisitos indispensables que será sometida a revisión dinámica con regularidad.

9. La certificación Herity se otorgará a todos aquellos lugares patrimoniales que posean los requisitos mínimos para optimizar las metas descritas en los puntos 4-7.

10. La secretaría de Herity mantendrá un registro de lugares certificados de consulta fácilmente accesible a todos los interesados.

Matilde González Méndez

Laboratorio de Arqueología

Instituto de Estudios Galegos

Padre Sarmiento

\section{Bibliografía}

BERNADAS, J. M. 1999. "La cultura del lleure: un nou jaciment per a I' arqueologia? Una reflexió sobre I' ús del patrimoni en activitas turistiques". Cota Zero, 15: 74-83.

CLEERE, H. 1993. "Managing the archaeological heritage". Antiquity, 67: 400-5.

GONZÁLEZ MÉNDEZ, M. 1995. "La concepción de un proyecto de valorización social del patrimonio arqueológico. El plan de Toques como referente". Archivo Español de Arqueología, 68: 225-243.

1997-8. "El vestigio como atracción del turismo, la interpretación como atracción del vestigio". Anales de Prehistoria y Arqueología 13-14: 289-300.

RUíz, R. Y RUíz. A. 2002. "Hacia una pedagogía para el conocimiento del patrimonio histórico a travñes de los itinerarios". En WVAA: III-IV y V Jornadas andaluzas de difusión. Consejería de Cultura, Junta de Andalucia; págs. 159-189.

QUAGLIUOLO, M. 2002 "Qualità nella gestione di un bene culturale: il riconoscimento HERITY". En Atti del VI colloquio internazionale La gestione del patrimonio culturale. Barletta 4-8 diciembre 2001; págs. 250-254.

TZANIDAKI D. J. \& VICINZINO, S. 2002. "Quality standars and their application to Cultural Heritage". En Atti del VI colloquio internazionale La gestione del patrimonio culturale. Barletta 4-8 diciembre 2001; págs.234-242.

Más información sobre el proyecto:

Laboratorio de Arqueología

Instituto de Estudios Galegos Padre Sarmiento

Centro Mixto CSIC-Xunta de Galicia

Edificio Monte da Condesa

Campus Sur

15706 Santiago de Compostela

Correo electrónico: pharpa@usc.es 